abnormalities with a bisatellited marker derived from chromosome 22. Am J Med Genet 1993; 47: 925-930.

2 Haab O. Bieträge zu den angeborenen Fehlern des Auges. Von Graefe's Arch. Ophthalmol 1878; 24: 257.

3 Gerald PS, Davis C, Say BM, Wilkins JL. A novel chromosome basis for imperforate anus (the 'cat's-eye syndrome'). Pediatr Res 1968; 2: 297.

4 Rosias PR, Sijstermans JM, Theunissen PM, PullesHeintzberger CF, De Die-Smulders CE, Engelen JJ et al. Phenotypic variability of the Cat Eye Syndrome. Case report and review of the literature. Genet Counsel 2001; 12(3): 273-282.

5 Denavit TM, Malan V, Grillon C, Sanlaville D, Ardalan A, Jaquemont ML et al. A new case of severe clinical phenotype of the Cat Eye Syndrome. Genet Counsel 2004; 15(4): 443-448.

6 Kalpakian B, Choy AE, Sparkes RS, Schreck RR. Duane Syndrome associated with features of the Cat-Eye Syndrome and mosaicism for a supernumerary chromosome probably derived from number 22. J Paediatr Ophthalmol Strabismus 1988; 25: 293-297.

7 Weleber RG, Walknowska J, Peakman D. Cytogenetic investigation of Cat-Eye Syndrome. Am J Ophthalmol 1977; 84: 477.

8 Mitchell PR, Parks MM. Ophthalmic syndromes and trauma. In: Jaeger EA, Tasman WS (eds). Duane's Ophthalmology. Lippincott Williams and Wilkins, New York, 2005, pp 1-6.

TN Win', Selwyn Roberts ${ }^{2}$ and David Laws ${ }^{1}$

${ }^{1}$ Department of Ophthalmology, Singleton

Hospital, Sketty Lane, Sketty, Swansea, UK

${ }^{2}$ Department of Cytogenetics, Institute of Medical Genetics, University Hospital Wales, Heath Park, Cardiff, UK

Correspondence: David Laws, Department of Ophthalmology, Singleton Hospital, Sketty Lane,

Sketty, Swansea SA2 8QA, UK

Tel: + 441792 205666, ext 5912;

Fax: + 441792205666.

E-mail: dave@sailwave.com

Eye (2007) 21, 289-291. doi:10.1038/sj.eye.6702538;

published online 22 September 2006

Sir,

\section{Palpebral pleomorphic rhabdomyosarcoma in a teenager}

Rhabdomyosarcoma (RMS) is the most common childhood primary soft tissue sarcoma. Ocular lesions represent about $10 \%$ of all RMSs. The majority of ocular
RMS arises from the orbit and is of the alveolar cell type. Pure eyelid lesion of the pleomorphic cell type is extremely rare especially in children. We would like to present a case of palpebral pleomorphic RMS and its management.

\section{Case report}

An 11-year-old Indonesian Chinese boy who was previously well, developed an itchy lump in his left upper lid in December 2004. The lump was excised at a local hospital in February 2005 without histological diagnosis. The lump recurred 3 months later resulting in a mechanical ptosis. The patient consulted a private ophthalmologist in Kuching, Sarawak in August 2005 and the lump was biopsied. Histology showed pleomorphic cells with enlarged hyperchromatic nuclei and eosinophilic cytoplasm. Some tadpole-shaped cells were also seen (Figure 1). The diagnosis of RMS was confirmed with immunohistochemistry, which revealed the presence of desmin (see inset in Figure 1). The patient was referred to the oncologist. CT scan of the orbits and brain showed the tumour was confined to the upper lid measuring $2.5 \times 3.0 \times 3.5 \mathrm{~cm}$. He was started on chemotherapy and two cycles of uncomplicated chemotherapy were given in August and September 2005. However, the tumour failed to respond to the treatments and doubled in size (Figure 2). Central necrosis also developed on the surface of the tumour.

The patient was referred to our eye centre for further management. Despite difficulty in opening the eye, the patient was able to perceive light in the left eye.

A repeated CT scan showed the tumour had extended into the anterior orbit (Figure 3). However, the orbital bone showed no signs of involvement. Using the

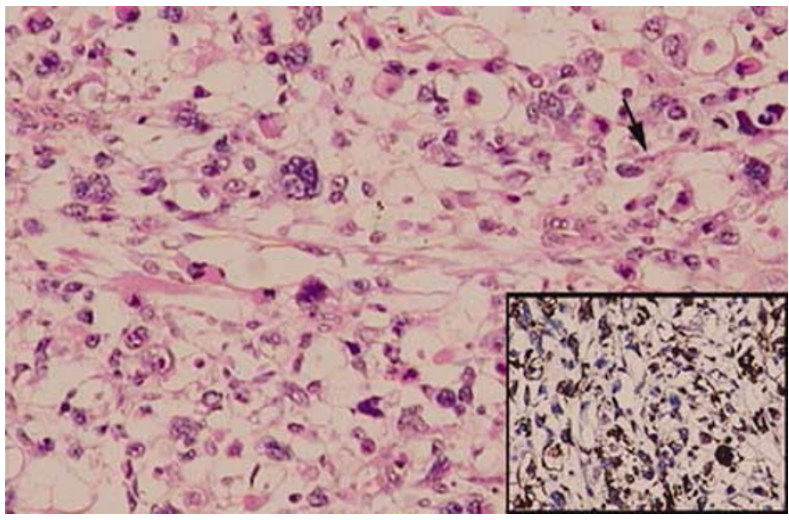

Figure 1 Histology of the tumour showing pleomorphic cells with tadpole-shaped cell (arrowed) and the inset shows positive desmin immunostaining of the tumour cells. 


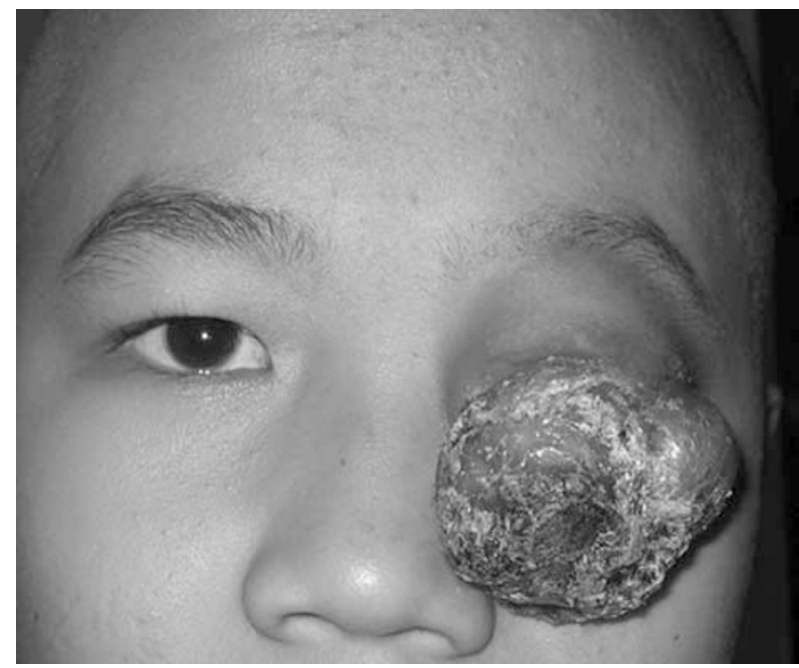

Figure 2 Pre-operative picture showing a large fungating tumour involving the left upper eyelid.

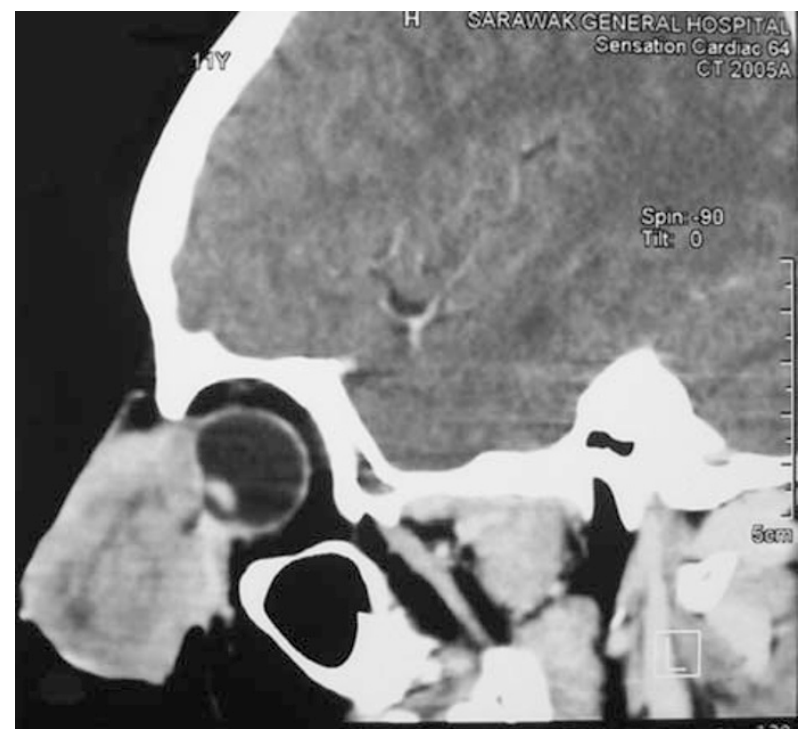

Figure 3 Sagital CT scan showing a large tumour of the upper eyelid extending into the anterior orbit.

Intergroup Rhabdomyosarcoma Study (IRS) Group Staging Classification, the tumour was staged as Group III.

The tumour was excised with a narrow margin. Except for a small stump of the lateral eyelid, the whole of the upper eyelid and the upper medial canthus was excised. The globe appeared intact except for a central leucoma from pressure keratopathy. There was no relative afferent papillary defect. Reconstruction of the upper lid was achieved with a combination of CutlerBeard's technique and glabellar flap. An MRI scan

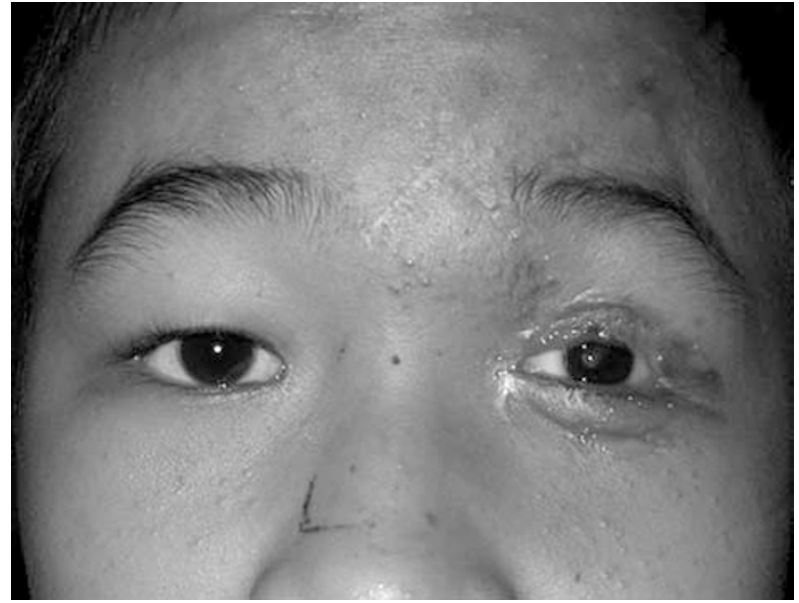

Figure 4 Post-operative picture at 6-month review.

4 weeks post-surgery showed no recurrence and the eyelid was opened 6 weeks post-surgery. A Frontalis suspension with $2 / 0$ prolene was performed simultaneously. He underwent adjunctive radiotherapy to eradicate any residual tumours. The patient remained well and the MRI scan showed no recurrence at followup (Figure 4).

\section{Comment}

Ocular RMS is the most common soft tissue malignancy in childhood. Compared with RMS of other parts of the body, ocular RMS has a better prognosis because of its earlier presentation. ${ }^{1}$ RMS can involve any part of the ocular tissue but pure eyelid involvement as in our patient is rare; most cases of reported eyelid RMS represent subcutaneous extension of the anterior orbital RMS. A recent review of the clinical spectrum of 33 paediatric patients by Shields etc ${ }^{2}$ showed that the orbit is the most commonly involved (76\%) followed by conjunctiva $(12 \%)$, uveal tract $(9 \%)$, within the globe $(9 \%)$, and eyelid (3\%). The other unusual aspect of our patient is the pleomorphic cell type; childhood RMS of the orbital region is of either the more common embryonal or the less common alveolar variety. Pleomorphic RMS rarely affects children and its occurrence in the orbit is extremely rare. ${ }^{3}$ Pleomorphic RMS typically affects adults older than 45 years of age and involves the peripheral skeleton. Histologically, it is important to differentiate pleomorphic RMS from other pleomorphic sarcoma. Histologically, the tumour exhibits tadpole-shaped rhabdomyoblasts with granular cytoplasm. Cross-striations are uncommon. Confirmation of the diagnosis is helped with positive immunohistochemistry stainings for desmin, glycogen, 
and myoglobin, which indicates the tumour exhibits skeletal muscle differentiation.

Over the past decades, great progress has been made in the treatment of RMS. The 5-year survival rates increased from $25 \%$ in 1970 to $73 \%$, as shown in the IRS-IV reported in $2001 .^{4}$ As most RMS is sensitive to chemotherapy and radiotherapy, exenteration is now rarely performed except for advanced or recurrent cases. The amount of tissue removed during biopsy is controversial but most ophthalmologists believe only a small biopsy is needed as orbital RMS has a favourable prognosis following radiation and chemotherapy, regardless of the amount of tissue removed. However, some prefer complete, or near complete, surgical removal when that can be achieved without major damage to vital structures like the optic nerve and extraocular muscles. ${ }^{5}$

Our patient with pleomorphic RMS did not respond to chemotherapy and the tumour grew rapidly. Excision of the tumour was the only option to check the relentless growth of the tumour. Although childhood RMS in general has been shown to respond to chemotherapy in IRS trials, most of these RMS are of either the embryonal or alveolar histological types. Studies showed that the presence of pleomorphic cell type is associated with poorer response to chemotherapy and prognosis. ${ }^{6,7}$

In summary, this case illustrates our experience in the management of a rare case of palpebral pleomorphic RMS, which failed to respond to chemotherapy and required complete surgical excision to control the disease process.

\section{Acknowledgements}

We have no financial interest in this case and this case has never been published or presented elsewhere.

\section{References}

1 Rousseau P, Flamant F, Quintana E, Voute PA, Gentet JC. Primary chemotherapy in rhabdomyosarcomas and other malignant mesenchymal tumors of the orbit: results of the International Society of Pediatric Oncology MMT 84 Study. I Clin Oncol 1994; 12: 516-522.

2 Shields CL, Shields JA, Honavar SC, Demirci H. Clinical spectrum of primary ophthalmic rhabdomyosarcoma. Ophthalmology 2001; 108: 2284-2292.

3 Shields JA, Shields CL. Rhabdomyosarcoma: review for the ophthalmologist. Surv Ophthalmol 2003; 48(1): 39-57.

4 Crist WM, Anderson JR, Meza JL, Fryer C, Raney RB, Ruymann FB et al. Intergroup rhabdomyosarcoma study IV: results for patients with nonmetastatic disease. J Clin Oncol 2001; 15: 3091-3102.

5 Lawrence Jr W, Hays DM. Surgical lessons from the Intergroup Rhabdomyosarcoma Study. Natl Cancer Inst Monogr 1981; 4: 159-163.

6 Kodet R, Newton Jr WA, Hamoudi AB, Asmar L, Jacobs DL, Maurer HM. Childhood rhabdomyosarcoma with anaplastic (pleomorphic) features. A report of the Intergroup Rhabdomyosarcoma Study. Am J Surg Pathol 1993; 17(5): 443-453.

7 Komdeur R, Klunder J, van der Graaf WT, van den Berg E, de Bont ES, Hoekstra HJ, Molenaar WM. Multidrug resistance proteins in rhabdomyosarcomas: comparison between children and adults. Cancer 2003; 97(8): 1999-2005.

M Alhady, CT Ngo, AK Tan, GK Swethadri and CN Chua

The Ophthalmology Unit, Universiti Malaysia

Sarawak (UNIMAS), Kuching,

Sarawak, East Malaysia

Correspondence: CN Chua,

Ophthalmology Unit,

Universiti Malaysia Sarawak (UNIMAS),

Lot 77, Seksyen 22 Kuching Town Land District,

Jalan Tun Ahmad Zaidi Adruce, 93150 Kuching,

Sarawak, East Malaysia

Tel: + 128908 877;

Fax: + 128908877 .

E-mail: chuaoxford@hotmail.com

Department where the work was carried out: Sarawak General Hospital, Kuching

Tel: + 012 8908877;

Fax: + 6082422564 .

E-mail: chuaoxford@hotmail.com

Eye (2007) 21, 291-293. doi:10.1038/sj.eye.6702541; published online 1 September 2006

Sir,

Cessation of migraines in a woman with low-tension glaucoma following the use of latanoprost: a favourable side effect?

Latanoprost is a phenyl-substituted isopropyl ester of prostaglandin $\mathrm{F}_{2 \mathrm{a}}$, effective in low-tension glaucoma (LTG), lowering intraocular pressure (IOP), improving pulsatile ocular blood flow, and increasing ocular perfusion pressure. ${ }^{1-2}$ Adverse topical effects such as anterior uveitis, cystoid macular oedema, conjuctival hyperaemia, and pigmentation of intra- and extraocular structures have been reported. ${ }^{3}$ Systemic side effects are rare but may occur such as facial rash, cardiovascular effects, ${ }^{4}$ and headaches. ${ }^{5}$

We report a favourable side effect of latanoprost in a woman with LTG. She reported complete cessation of her migraines after the use of latanoprost. She remained free of episodes of migraines for more than 1 year.

Satisfactory challenge and rechallenge were performed. 